\title{
Thoughts on the Design of Wall Painting Patterns for the Tourism Space
}

\author{
Hao Yan ${ }^{1 \mathrm{a}}$, Gao $\mathrm{Xu}^{2 \mathrm{~b}}$, Huang Gonghu ${ }^{3 \mathrm{c}}$ \\ ${ }^{1}$ Institute of Design and Art of Shenyang Jianzhu University, 25 Wenhua East Road, Hunnan District, Shenyang, Liaoning, China \\ ${ }^{2}$ Editorial Department of Journal of Shenyang Jianzhu University, Shenyang, Liaoning, China \\ ${ }^{3}$ Institute of Design and Art of Shenyang Jianzhu University, Shenyang, Liaoning, China
}

\begin{abstract}
The rapid development of economy in the modern society have led people to develop more and more demands for spiritual life, and has gradually changed people's way of life. The rise of tourism industry has also met some people's spiritual needs, with the tourism space becoming part of the humanistic landscape. The needs of people for tourism space vary from time to time, which are further complicated by people's demand for more public space. The growing ecological awareness of people are driving them to focus more on the tourism space, allowing them to learn about different geologies, cultures and histories so that they could relax and ease off anxiety brought by the hustle and bustle of city life. Therefore, public tourism space has become a major component of city in urbanization.
\end{abstract}

\section{Introduction}

In the current social life, the pace of people's work and life is getting faster and faster, tension and anxiety also spread. Many people take mitigation measures-tourism, this activity alleviates the irritability caused by this fast pace. Therefore, in the process of tourism, people's attention to the space environment is also increasing. This requires more than a simple built environment, But also requires the spiritual and cultural needs attached to the carrier of architecture. In the article we propose to incorporate graphic art into architectural design, enrich the connotation of architecture, increase people's interest. But how to integrate traditional graphic art is a problem we think about. We will select the components that make up the building-wall space. Discuss it as the content of a point, we will analyze that the wall is in different spaces bring people different feelings and how to integrate the pattern art in traditional culture in different functional spaces.

\section{The role of Wall and Wall Surface in the Design of Public Space}

\subsection{The history of "walls"}

In the profound history of China, the perceptions of "walls" among places of distinct geographical features recorded traditions and histories of different ages as well as social behaviors of people at those times. It is not only a part of the building, but also serves historical functions with the progress of the times. More than just a defense and enclosure, the walls cater to the mental needs of people and serve as a social communicator with multiple functions, and therefore playing an increasingly important role in the public space of cities.

\subsection{The role of wall surface in the design of public space}

As an enclosure of the open space, the wall surface forms a boundary in our daily life, serving as a powerful visual guide. A deep space could be created in a closed or open space by the play of visual techniques, endowing the space with vitality. The subjects of the wall painting, with its materials, colors and forms, and the space transitions brought by visual techniques, could stimulate the visual sensory of people.

The wall surface, like the red wall of palaces, the yellow wall of Buddhist temples, and the white wall of the Jiangnan Watertown, is incorporated into the space design and depicts the geographical features and local culture of the region. Zhaobi, as mentioned in ancient geomantic omen, is an important part of Chinese traditional architecture, with specific functions and aesthetic value. In today's tourism space, the wall remains a carrier of local culture and history, highlighting the long-standing traditional culture of China. The presentation of culture in the form of wall painting has been common in the tourism space. When people travel, Chinese traditional culture will be inherited and carried forward.

The wall is an important component of all spaces. As the side of the space, they all appear in the vertical form, which has great influence on people's vision. Therefore, the design and application of wall surface is of significance to the public space. In different public spaces, there are different requirements for wall design. For 
spaces with different functions, the design needs to be adapted to meet people's needs.

The design of public space should give full consideration to the role of walls, including the selection of materials, shapes, colors and patterns.

Public space is particularly precious in cities. For Chinese people with a long history of culture, they are interested in how to make a good use of traditional patterns-a heritage of Chinese traditional culture to create a decent public space for the city, bring a better life for the citizens, and improve the urban public space through wall painting.

The paper focused on public space for leisure to study tourist space and investigated what changes and feelings the wall design has brought to people. The key to the design and construction of this kind of public space should be based on people's needs and expectations, featuring flexibility, comfort, safety and full integration with the city.

\section{Thoughts on Traditional Patterns in Wall Painting Design}

\subsection{Types of traditional patterns}

Traditional patterns, an important part of Chinese traditional culture, carry a lot of historical inheritance. In these patterns, we can see the progress of history, the development of economy, the embodiment of regional characteristics, local customs and the changes of the sceneries in four seasons.

In the existing classification of traditional patterns, there are several common patterns.

The subjects of the painting include human being, animal, plants and sceneries. As for carriers of the patterns, there are potteries, bronze wares, wood carving, porcelains, stones and bricks, silk, and gold and silver wares. It can also be classified based on dynasties.

\subsection{Selection and arrangement of traditional patterns}

The design carries the inheritance of culture, and embodies contemporary social characteristics. It is the designer's duty to properly combine the tourism space with Chinese traditional culture. There are several ways to apply the pattern elements in traditional culture to the design of tourism public space:

\subsubsection{Summary and arrangement}

There are traditionl patterns with overcomplicated meanings inaccessible to the public. Therefore, it needs to be sorted out and summarized by the users. It can be integrated with diversified modern styles to fully reflect the charm and connotation of contemporary social spiritual culture.

\subsubsection{Direct application}

There are traditional patterns that are concise and clear in meanings, which can be directly applied to wall painting.

\subsubsection{Refinement}

There are traditional patterns whose implications and ornamentation images can be refined to better meet the needs of contemporary design requirements.

\subsection{Application of traditional patterns in interior decoration design}

The economic development promotes the prevalence of the home decoration industry. While the western decoration style expands the vision of Chinese people, the traditional Chinese cultural could better express Chinese people's aesthetic values and emotions. Traditional patterns provide fertile ground for this purpose as it conveys the needs of different spaces with its unique language and expressions. Wall painting using traditional Chinese patterns in indoor public space serves to deliver Chinese culture to visitors to this space. such as Figure 1 we see some comparative data in the figure: 


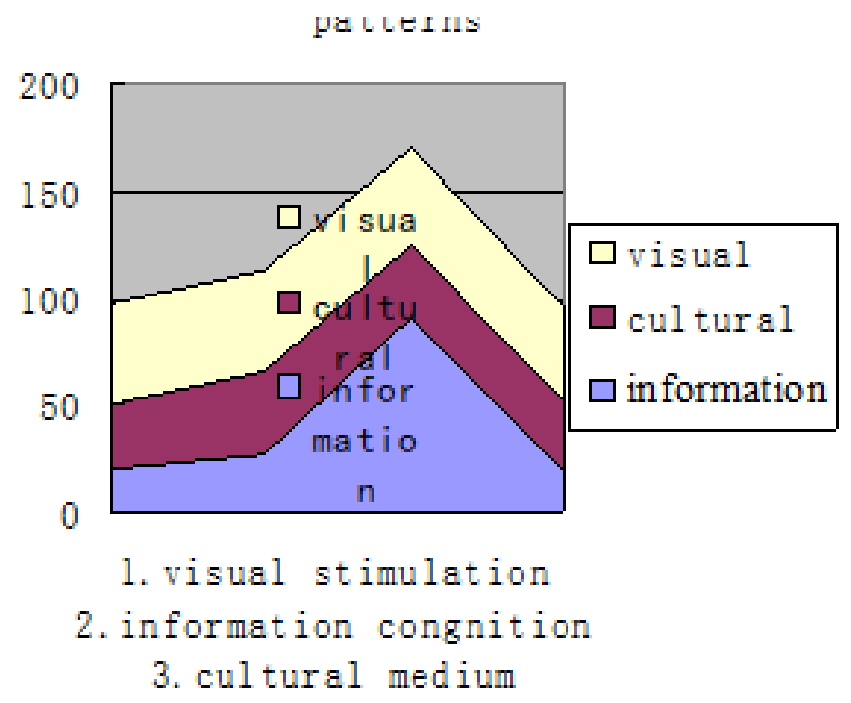

Fig 1. Comparison of the sensory stimulation brought by patterns

Wall painting has a rich and colorful history in China. These historical resources can serve as tourism resources to inform people of the historical development of China. There were large wall paintings in the Han Dynasty, showing mythical stories and secular life in that era. During the Wei and Jin Dynasties, the introduction of Buddhism created a large number of religious wall paintings.

The contemporary wall painting is an extension of traditional wall painting, and also a new art media of our times. It continues the color and beauty of ancient wall paintings, and represents people's aesthetic pursuit and emotional expressions by telling stories in the form of wall paintings. It not only retains the aesthetic functions of wall paintings, but also plays a decorative effect. We can make a comparison with a chart, such as Figure 2: Comparison of wall painting in space environment.

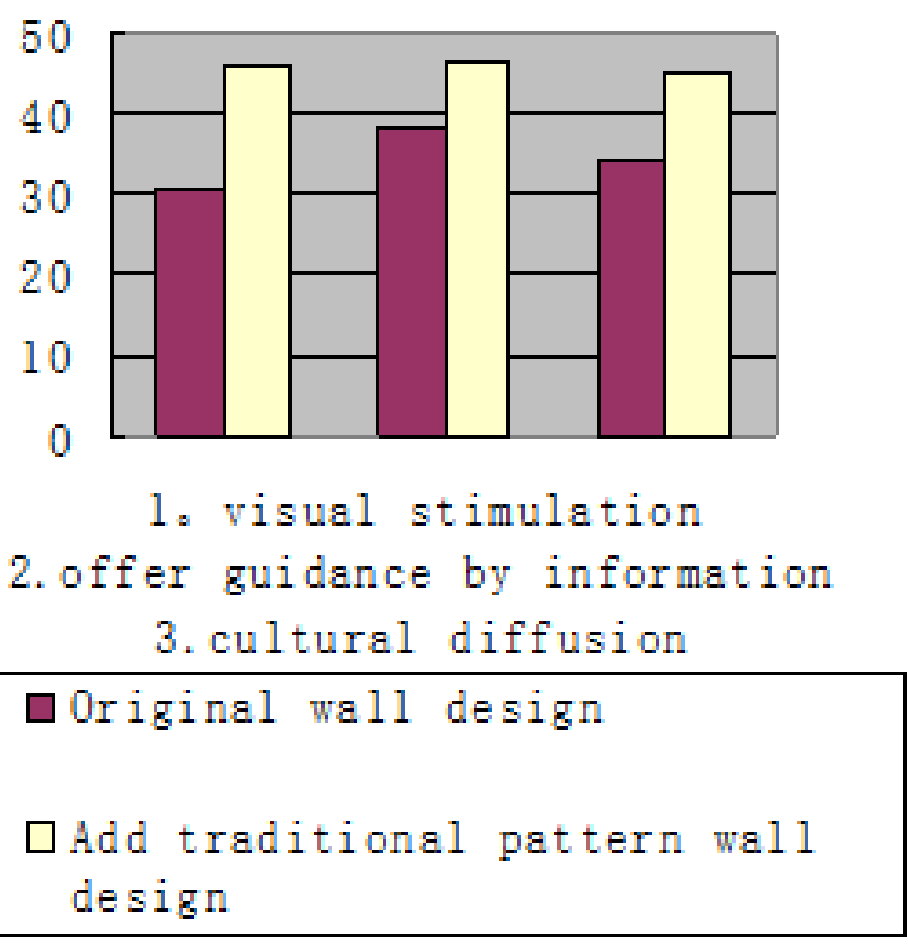

Fig 2. Comparison of wall painting in space environment

The decorative function is the most prominent feature of wall paintings. "Decoration is a way for human beings to know the world, and it reflects a visual need of people. The essential feature of decoration-the sense of form, is based on people's perception of basically the same form and structure (2). Wall painting is not only the partial decoration of wall, but also improves the whole space, meeting people's aesthetic and visual needs. This brandnew decorative art embodies the inner feeling of life and beauty in visual expression. By presenting three- 
dimensional and vivid pictures with historical significance on the wall, it creates the aesthetic feeling of living space in a highly expressive and interesting form, thus attracting and inspiring people.

\section{Conclusion}

Moderate decoration can help people better understand the nature of architectural space. In China, an ancient civilization with a long history, it is necessary to meet the requirements of space decoration and reflect our national and ethnic characteristics. Therefore, traditional Chinese patterns are one of the indispensable elements in design. The diversified space components have become an important part of modern decoration. The wall design of tourism space can not only satisfy people's aesthetic needs, but also enhance the cultural atmosphere of the space. The diversification and individuation of wall design in tourism space are often formed in a specific social and cultural context, with distinct spiritual and cultural connotations to describe social and cultural features at that time and represent different aesthetic values. In the long history of China, patterns are commonly found on buildings, which spread the thoughts and culture of the present era. We should work hard to meet people's aesthetic needs of visual arts in the wall design of public space. To better reflect traditional Chinese culture, we need to take this idea as the foundation of design, and fully reflect the spirit of nation and contemporary society in the design.

\section{References:}

1. Peng Jixiang, Chinese Art, Peking University Press, January 2007

2. Integration of Chinese Decorative Patterns, Liaoning Fine Arts Publishing House, January 2001

3. Chen Bochao \& Park Yushun, Shengjing Palace Architecture, China Building Industry Press, 2007.

4. Decorative Anthology (Historical Space Volume III), Editorial Department of Decoration Magazine, Liaoning Fine Arts Publishing House, March 2017

5. Luo xiusheng, The Manchu Paper-cut in XiuYan, A series of books on statelevel non-material cultural heritage in Xiuyan, Liaoning Fine Arts Publishing House, January 2014

6. Luo xiusheng, The Shadow Play in XiuYan, A series of books on statelevel non-material cultural heritage in Xiuyan Liaoning Fine Arts Publishing House, January 2014

7. Gu shangli, Environmental Protection and Tourism Development, Tourism Newsletter magazine, 1994

8. Fu wenwei, Development of Tourism and Environmental Management, Tourism science magazine, 1992

9. Yang zaitian, Chinese tourism geography, Science Press, 1999 